\begin{tabular}{|c|c|c|}
\hline $\begin{array}{l}\text { PKS } \\
\text { PUBLCC } \\
\text { KNOLLEDEG } \\
\text { PROECC }\end{array}$ & $\begin{array}{c}\text { Revista de GEOGRAFIA } \\
\text { (RECIFE) } \\
\text { http://www.revista.ufpe.br/revistageografia }\end{array}$ & 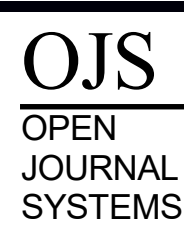 \\
\hline
\end{tabular}

\title{
PODER PÚBLICO E RESSIGNIFICAÇÃO: O PARQUE MADUREIRA NA TRANSFORMAÇÃO DA PAISAGEM CARIOCA
}

\author{
Pablo de Oliveira Carneiro ${ }^{1}$ \\ ${ }^{1}$ Mestrando em Geografia na Universidade Federal do Rio de Janeiro. Email: pocarneiro@gmail.com \\ Artigo recebido em 28/08/2017 e aceito em 01/10/2017
}

\begin{abstract}
RESUMO
Diante das obras estabelecidas na cidade do Rio de Janeiro para a realização dos Jogos Olímpicos 2016, o poder público em suas diferentes escalas buscou estabelecer suas narrativas que melhor justificassem os gastos públicos e lhes capitalizassem politicamente. Nesse trabalho tomamos uma parte dessas obras, a construção do Parque Madureira, no subúrbio da cidade, como objeto para analisar a evolução e construção de um discurso oficial por parte do poder público. O objetivo foi investigar como a Prefeitura, em sua multiplicidade de atores envolvidos, construiu uma série de discursos que transformam a forma como a paisagem do bairro e, consequentemente, da cidade são interpretadas. São antigos significados que são revistos, alguns revalorizados, outros invisibilizados e novos significados que surgem e buscam se estabelecer. Aqui três atores principais foram analisados o engenheiro Mauro Bonelli, responsável pela obra, o arquiteto Ruy Rezende, responsável pelo projeto, e o canal oficial de divulgação dos dados das obras pelo youtube. Nesse sentido foi possível observar divergências entre os interlocutores, bem como o quanto seus discursos se cruzaram e se transformaram no processo de construção do discurso oficial da Prefeitura.
\end{abstract}

Palavras-chaves: Narrativa da Paisagem. Discursos. Parque Madureira.

\section{PUBLIC AUTHORITY AND (RE)SIGNIFICATION: PARQUE MADUREIRA IN THE CHANGING PROCESS OF CARIOCA LANDSCAPE}

\begin{abstract}
In view of the works established in the city of Rio de Janeiro for the 2016 Olympic Games, public authorities at different scales sought to establish their narratives that best justify public spending. In this article we took one of these actions, the construction of Parque Madureira, in the outskirts of the city, as an object to analyze the evolution and construction of an official discourse by the public authority. The goal was to investigate how the City Hall, in its multiplicity of actors, constructed a series of discourses that transform the way that the neighborhood's landscape and, consequently, the city's landscape are interpreted. They were old meanings that were revalued, others invisibilized, and new meanings that arise and seek to establish themselves in the main ladscape. Here three main actors were analyzed by, first the engineer Mauro Bonelli, responsible for the work, the architect Ruy Rezende, responsible for the project, and then the official channel that propagate the works data through a youtube. In this sense it was possible to observe differences between the interlocutors, as well as how their discourses crossed and became a part in the process of construction of the official discourse of the City Hall.
\end{abstract}

Keywords: Landscape narratives. Discourse. Parque Madureira. 


\section{INTRODUÇ̃̃̃O}

A cidade do Rio de Janeiro carrega consigo um forte apelo turístico no país, após a mudança do Distrito Federal e com o avanço do processo de desconcentração industrial ficou cada vez mais relevante seu apelo turístico e a importância do setor para sua economia. Não por acaso nos últimos anos o poder público carioca investiu em vários projetos para valorizar esse potencial turístico. Exemplo dessas tentativas é a área portuária que recebeu projetos de instalação de prédios públicos, urbanização e visibilidade das áreas de favela até a mais recente operação urbana com museus, reformulação de fachadas e das áreas de circulação.

Esse processo da história urbana recente do Rio é muito semelhante ao que Peter Hall (1995) descreve para outras cidades no hemisfério Norte. Trata-se de um processo onde áreas marginalizadas da cidade passam a ser revalorizadas e ressignificadas em vista de uma ativação econômica, com retorno através de atividades turísticas ou imobiliárias. No Rio de Janeiro destaca-se o protagonismo do poder público municipal ao elaborar e financiar projetos como esses. Nesse contexto, a administração de Eduardo Paes (2009-2016) destacou-se não por intervenções inovadoras, mas pela estratégia de estruturação do projeto e criação de uma marca para a cidade.

Aproveitando a eleição da cidade como anfitriã para os Jogos Olímpicos de 2016, resultado de várias administrações municipais, surge da Prefeitura o projeto "Cidade Olímpica". Foi a reunião de todas as intervenções e obras públicas realizadas no município numa marca visível e identificável para a população, desde obras de calçamento de bairro até a construção de arenas. Os Jogos funcionavam como um catalizador para o esforço municipal, permitindo a construção de uma retórica que criava objetivos e missões, assim como a retórica do legado urbanístico. Para coordenar esse projeto foi criada a Empresa Olímpica Municipal, em 2011, ligada diretamente ao gabinete do prefeito, para sua primeira presidência foi nomeada Maria Silvia Bastos Marques com formação e atuação na administração pública. Em 2014, Joaquim Monteiro de Carvalho de formação em marketing e experiência a frente da área de esportes, assume a presidência. Fica, assim, mais explícita a iniciativa municipal na ação de city branding, procurando provocar ressignificações que resultem em reativações no setor econômico, como apontamos anteriormente.

Diante desse contexto o objetivo do presente trabalho é explorar como ações de intervenção do poder público são utilizadas como estratégias de ressignificação da paisagem da cidade. Isto é, como a prefeitura explora interpretações sobre a cidade e seus espaços, 
criando suas próprias narrativas e significados a serem difundidos para a população? Para cada uma dessas obras foi criada uma narrativa de justificativa, esforços de criação de propaganda e discursos feitos para transformar a forma como entendemos a cidade.

Como recorte assumimos o período da administração de Eduardo Paes (2009-2016), considerando a mobilização de marketing já citada. As ações da Prefeitura, por mais que sob a marca do "Cidade Olímpica" não se restringiam somente ao mobiliário para o evento, mas se espalharam pela cidade. Como estudo para esta pesquisa, adotamos a construção do Parque Madureira, em bairro homônimo afastado dos circuitos olímpicos e do centro da cidade, mas fortemente explorado pelo marketing. Contudo o objeto não é o parque em si, mas discursos criados a partir da intervenção da Prefeitura na sua construção. Esses discursos podem ser construídos por diferentes interlocutores, e aqui analisamos somente aqueles enunciados pela Prefeitura. Porém é preciso ressaltar que um discurso estar ligado à Prefeitura não significa ser produto de um interlocutor único e homogêneo, uma vez que o governo é fruto de um conjunto de diferentes atores, como especificaremos em seção própria do texto.

Antes de prosseguir, pois, é preciso esclarecer alguns pontos sobre o que consideramos como processos de ressignificação, da construção de narrativas e discursos. Como é possível entender que essas intervenções transformem a forma como as pessoas percebem a cidade?

\section{NARRATIVAS DA PAISAGEM E CONSTRUÇÃO DE SIGNIFICADOS}

A paisagem é um conceito antigo e pela extensão de trabalhos que a abordam, muito polissêmico, porém, atualmente três principais correntes podem ser identificadas, a da Ecologia da Paisagem, a Paisagem dos Arquitetos e a Paisagem da Arte. A Ecologia da Paisagem é um campo que se desenvolve a partir da Biologia, portanto será forte o aspecto natural na paisagem e o homem será visto muito como elemento estranho que causa danos à Natureza. Nesse campo a paisagem será vista como um recorte espacial, uma categoria que permite ver o espaço de forma a integrar suas diferentes dimensões, inclusive o homem e a natureza, permitindo um estudo de forma sistêmica (VERDUM et al., 2012). A paisagem dos arquitetos tem muitas semelhanças com a Ecologia da Paisagem, sobretudo a ênfase que se dá há relação homem-natureza, onde a presença de aspectos naturais visíveis (vegetação, água, rochas, etc.) é fundamental para a configuração da paisagem. Entretanto a origem do conceito para a arquitetura é bem diferente, com raízes na história da arte e não na biologia, o que dá valor ao espaço circunscrito, um recorte espacial que pode ser muito menor que o espaço 
sistêmico da ecologia. $\mathrm{O}$ jardim é a figura central na paisagem do arquiteto pois expressa mais diretamente a natureza num espaço do homem e de forma controlada, construído (VIEIRA, 2007). Na perspectiva da Arte o conceito de paisagem vem do enquadramento das pinturas, assim a ideia de recorte e da representação estão sempre presentes, com forte influência do aspecto visível. Essa paisagem seria pois uma forma de olhar o espaço, a seletividade seria parte fundamental da paisagem (RIBEIRO, 2011).

A terceira abordagem, vinda da arte, será a principal influência para o campo de estudo da geografia humana, tendo sido muito trabalhada pelos geógrafos como aquilo que está ao alcance da visão (SANTOS, 1996; SAUER, 1998). Essa perspectiva limita sua utilização e sobrevaloriza sua materialidade, uma vez que mesmo que se possa admitir a manipulação dessa visão, ela ainda é tida como central. A Nova Geografia Cultural, ao criticar a geografia cultural empirista fundada por Sauer abre novas possibilidades teóricas para se trabalhar cultura e paisagem (DUNCAN, 2012). É a partir dessas possibilidades que Duncan (2004) busca se afastar do empirismo saueriano e trazer uma maior discussão teórica sobre o conceito de cultura, associando o campo da geografia a outras ciências. O autor concebe um conceito de paisagem como construção cultural da mente humana, mais do que a materialidade do espaço, a paisagem será um sistema de significados fruto da percepção alcançada por todos os sentidos e influenciada também pelas diferentes pessoas com as quais uma pessoa se relaciona. Segundo Duncan (2004) também, o conjunto de elementos simbólicos da paisagem transmite um sistema de signos e uma ordem social às futuras gerações por meio de um conjunto material que lhe é próprio. Para ele esse sistema de signos pode ser visto como sistema de textos, definindo uma textualidade e que permite estudá-la a partir dos discursos que são criados para preenchê-la. Em outro texto, sobre discursos, coloca que:

Discursos contêm cargas morais e uma frágil devoção que liga as paisagens aos lugares, e estes a estilos de vida e ideologias políticas e religiosas, transformando-os todos numa estética dominante. (DUNCAN, J.; DUNCAN, N., 2004, p. 38, tradução do autor).

A partir da perspectiva de Duncan, Ribeiro (2011) entendeu que um mesmo espaço tornado paisagem poderia gerar narrativas diferentes, isto é, a partir do olhar particular que uma pessoa lançasse a ele certos significados seriam destacados, sendo possivelmente

\footnotetext{
1 "Discourses contain morally charged tales and loosely linked pieties that connect landscapes to places and places to lifestyles and political and religious ideologies, shaping them all into a dominant aesthetic." 
diferente daqueles destacados por outros grupos. Em texto mais recente este vai além e coloca que a paisagem não é somente um significante, como ela própria é um significado:

Ao contrário de alguns autores da nova geografia cultural que afirmam que as paisagens possuem significados simbólicos, defendo que a paisagem é um significado simbólico. É o olhar, o sentir e a interpretação que transformam o espaço em paisagem. A paisagem não é o que se vê e o que se sente, mas como se vê e como se sente. (RIBEIRO, 2013, p. 252).

Essa perspectiva de paisagem enquanto narrativa, fruto de um conjunto de discursos organizados em formar e transmitir um sentido, nos ajuda a compreender como um objeto de intervenção pública pode ser explorado como estratégia de ressignificação para transformar a forma como uma pessoa percebe a cidade. Isto é construir uma narrativa de paisagem, com sua lógica interna e conjunto de significados, é criar uma forma de ver, enquadrar e também sentir o espaço da cidade. Essa narrativa, pela sua difusão e publicização tende a ser percebida por outros grupos, podendo ser absorvida inteira ou parcialmente, ser refutada por outras narrativas ou ser transformadas por outros atores. Para além dessa mistura de discursos, seu espaço de conflito, o que é relevante para essa pesquisa no momento é a capacidade dessa criação de narrativas de construir significantes e eleger elementos carregados de sentidos a serem (re)valorizados na paisagem.

Durante o desenvolvimento desse trabalho foi possível observar parte do que seria essa esfera de conflito das narrativas. Uma vez que um mesmo elemento recebe uma valorização diferente por dois atores, com justificativa e objetivos diferentes, a forma como outros atores podem receber esses significados pode ser distintas, transformando essa narrativa. Ainda que não seja o objetivo central do trabalho foi possível tangenciar elementos como esses a partir da análise de conteúdo dos discursos apresentados.

\section{METODOLOGIA DE ANÁLISE}

Como discutido anteriormente, diferentes atores são responsáveis pela criação dos discursos sobre a cidade e contribuem para a forma como outras pessoas a observam. Visando estudar a criação do Parque como obra de diferentes atores, uma importante opção metodológica é a interpretação de Rossi e Vanolo (2011) sobre a política na cidade. Estes consideram a política urbana como composta por três esferas, complementares, mas 
autônomas: 1) governo, do aparato estatal com sua inteligência de governo; 2) representação, da produção de imagens e discursos; 3) contestação, dos movimentos de resistência à política dominante. Essa visão permite uma melhor observação que existem tanto aqueles atores inclinados ao discurso da Prefeitura, e aqueles mobilizados a uma resistência que disputam espaço numa esfera de representação.

Das três esferas, a representação é central para esse trabalho e nosso objeto de investigação. É nela que os diversos grupos e atores disputam a construção de narrativas, seja do espaço em que vivem (formando narrativas de paisagem) seja da imagem que formam um do outro. Nesse sentido Bourdieu pode ser de grande auxílio, quando coloca que:

o [discurso] oficial é o público: é a ideia que o grupo tem de si mesmo, e a ideia que ele pretende professar de si mesmo, a representação (...) que ele pretende dar de si mesmo quando se apresenta como grupo (BOURDIEU, 2014).

Isso nos apresenta como a representação e o discurso enunciado estão muito ligados à ideia de publicidade, ou seja, daquilo que é exposto ao público, difundido. Os discursos construídos, ainda que produzidos pela intervenção de uma comissão, precisam ser publicados, ou seja, se tornar públicos ou por meio de uma enunciação ou por arquivo impresso. Portanto, para alcançar o objetivo traçado aqui de identificar os novos discursos, considero trabalhar com as fontes publicadas para divulgação dos aspectos do parque.

Dentro do universo amplo de publicações e divulgações que temos e dos limites de recursos dessa pesquisa restringi o material trabalhado. Primeiro foi delimitado que, dentro dos objetivos desse trabalho, a questão central é como a esfera de governo mobiliza a esfera de representação para a criação de seus discursos. Portanto o primeiro objeto de análise serão as publicações oficiais, este é complementado por publicações feitas por outros dois atores principais responsáveis pela elaboração e divulgação do projeto do Parque. Isto nos leva a delimitar três atores.

O primeiro é a figura oficial da Prefeitura, que divulga boa parte de suas ações a partir do site "Cidade Olímpica", , de onde extraí projetos e reportagens. O segundo ator, Mauro Bonelli, recebe destaque pela sua função de engenheiro responsável pela obra, com contribuição pessoal a partir de dissertação de mestrado defendida em $2013^{3}$. Por fim, a

\footnotetext{
${ }^{2}$ Disponível em: http://www.cidadeolimpica.com.br

${ }^{3}$ BONELLI, M. C. Sustentabilidade em Obras Públicas: O caso do Parque Madureira. 2013. 124 f. Dissertação de Mestrado - PUC-Rio, Rio de Janeiro, 2013. Disponível em: http://www.urb.pucrio.br/dissertacao/dissertacao_mauro_bonelli.pdf 
terceira fonte vem da equipe de arquitetura, o escritório Ruy Rezende Arquitetura (RRA), que produziu palestras e publicações sobre o projeto. É necessário esclarecer aqui que todas essas fontes foram consultadas até dia 31 de janeiro de 2015, data em que se iniciou a etapa de análise desse trabalho, delimitando nosso recorte temporal.

Para prosseguir na análise desse material lanço mão da metodologia da análise de conteúdo, utilizada para interpretar o conteúdo de diversos documentos e textos. Praticamente todo material de comunicação, seja verbal ou não, pode ser analisado. A busca pelo sentido desse material pode ser feita a partir de uma análise quantitativa ou qualitativa, ou, ainda, mista. Entretanto, independente da escolha, sabemos que nunca é garantida uma correspondência total de sentido entre o interlocutor e o leitor. O sentido percebido pelo leitor (ou pesquisador) pode coincidir com o que o autor busca expressar; pode não coincidir; pode ser captado de diferentes formas por leitores diferentes; ou pode ainda ter sido expressado um sentido do qual nem o autor estivesse consciente (OLABUENAGA \& ISPIZUA apud MORAES, 1999). Isso significa que o resultado da análise não é único, o que é reflexo do próprio objeto, já que nem a linguagem nem a leitura são neutras, e a interpretação é sempre passível de mudança e novos significados. Entretanto isso não é algo que invalide a pesquisa.

Moraes (1999) define que as pesquisas podem se dividir numa abordagem com ênfase dedutiva-objetiva ou intuitiva-subjetiva. Segundo o autor, isso tem menos a ver com falta de rigor científico da abordagem intuitiva, e mais relação com a busca pela abordagem qualitativa em ultrapassar o nível da mensagem manifesta - a explícita - e alcançar a mensagem latente - subjetiva - articulando a mensagem ao seu contexto cultural. Outra diferença é que a abordagem dedutiva-objetiva se caracteriza por procurar explicações e generalizações gerais a serem comprovadas pela análise, e para tanto estabelece categorias a priori na pesquisa. Enquanto isso a abordagem indutiva-subjetiva trabalha numa perspectiva construtiva, analisando primeiro os documentos para, e a partir disso formular suas categorias e conceitos de forma mutável ao longo da pesquisa.

Para o objetivo traçado nessa pesquisa a abordagem indutiva subjetiva se mostra muito mais útil. Isso significa uma análise mais qualitativa do que quantitativa, ainda que não excludente. A perspectiva construtivista possibilita também analisar se os discursos em cada fonte são semelhantes ou diferentes. Até porque ao contrário de utilizar as mesmas categorias para todas as fontes em busca de uma correspondência estrita, como seria a abordagem objetiva, procuro em cada fonte suas próprias categorias a partir da pré-leitura. 


\section{A CONSTRUÇÃO DE UM DISCURSO OFICIAL}

Como discutido anteriormente, o Estado é um agente importante na produção de discursos que, aproveitando-se de dispositivos seculares de poder, são difundidos e interpretados pela maioria das pessoas como legítimos uma vez que oficiais. Não podemos esquecer que o Estado não é o único a produzir discursos, mas tão pouco podemos considerar que este seja um ator monolítico, sem divisões internas. Discursos produzidos pelo Estado são fruto da disputa interna de diferentes atores que participam de sua gestão e ações. Portanto, antes de prosseguir é necessário definir cada um desses atores na Prefeitura, saber como se conectam e a influência que carregam.

O Parque foi realizado na gestão de Eduardo Paes, com projeto de responsabilidade da Secretaria Municipal de Urbanismo chefiada por Sérgio Dias, mas teve atuação de diferentes empresas. A principal delas é a Ruy Rezende Arquitetura Ltda (rra), que foi responsável pela definição da maior parte do projeto, fazendo os planejamentos de urbanismo, paisagismo e arquitetura (REZENDE et al., 2012). Entretanto contribuíram também Rio Ramp Design com o projeto do Skate Park e Soter Design, para programação visual do parque.

A construção foi de atribuição da empresa Delta Construções, porém seria orientada pela Secretaria Municipal de Obras secretariada por Alexandre Pinto da Silva. O funcionário da SMO encarregado da coordenação da obra foi Mauro Bonelli, funcionário municipal desde 1986, participando também ativamente dos vídeos de divulgação da Prefeitura. Em decorrência de sua participação no projeto, Bonelli desenvolveu e defendeu em 2013 uma dissertação na PUC-RIO intitulada "Sustentabilidade em Obras Públicas: O caso do Parque Madureira", para obtenção do grau de Mestre em Engenharia Urbana e Ambiental.

Desde a base do projeto a imagem do Parque Madureira foi associada à questão do meio ambiente pelos canais do projeto "Cidade Olímpica". Essa imagem foi reforçada com sua inauguração fazendo parte dos eventos programados para a reunião internacional de sustentabilidade Rio+20. Tal relação ficou gravada no nome oficial, sendo "Parque Madureira Rio+20" por decreto municipal e na administração do Parque na figura da Gerência do Parque Madureira Rio+20, sob o comando da Secretaria Municipal da Casa Civil.

A questão ambiental fica em evidência também no discurso de Bonelli, como poderia se esperar numa dissertação sobre engenharia ambiental. Bonelli acompanhou o projeto desde o início com a elaboração de seus objetivos, retratando essa experiência detalhadamente no 
texto. Para a análise desenvolvida aqui importou menos esses dados técnicos e mais os princípios e objetivos definidos e que compõe as justificativas para o parque.

Em seu texto oito discursos podem ser colocados em evidência. Para posterior análise e comparação com os discursos dos demais atores os nomes das categorias foram simplificadas para permitir melhor correspondência, mas mantêm-se algumas particularidades:

1. Gestão: este discurso remete às menções de eficiência das ações do poder público, às colocações das ações da Prefeitura como exemplares e de qualidade;

2. Sustentabilidade: correspondente às constantes menções aos conceitos de sustentabilidade tidos como princípio do projeto, é apreendido de forma geral como gestão de economia de recursos econômicos e ambientais, mas também trata da relação do entorno com o parque, numa ideia de harmonia da paisagem ou do espaço urbano;

3. Experiências Ambientais: termo cunhado por Bonelli, o discurso valoriza a relação homem-meio, inclui desde ações de sustentabilidade e recuperação ambiental a relações sensitivas de contato com os elementos, dando um caráter transcendente às experiências;

4. Recuperação Ambiental: apesar do termo utilizado por Bonelli ser recuperação urbana, todo seu conteúdo é de recuperação ambiental, tratando da melhoria do ciclo hídrico, remoção da poluição ambiental, relação com o entorno na criação de uma paisagem "não degradada". Insere-se nesse discurso também, mas não exclusivamente, a remoção das ocupações informais, observada como um problema de degradação ambiental;

5. Desenvolvimento Econômico: termo genérico para a valorização econômica que pode resultar das ações na área, podendo ser desde valorização direta do preço do solo, como maior afluxo de frequentadores ou maior movimentação do comércio;

6. Qualidade de Vida: melhoria da qualidade de vida cotidiana dos moradores ou frequentadores locais, o que engloba desde melhoria de saúde por esportes ou da qualidade do ar, até aumento das opções e atividades de lazer e sensação de felicidade;

7. Espaço Público: em Bonelli este discurso se constrói na forma da liberação de área verde pública para realização de atividades de lazer, ou seja, está muito ligado também à relação com o meio ambiente e a possibilidade de se ter "experiências ambientais";

8. Pertencimento: trata-se da construção de uma relação de pertencimento da população local com o Parque, majoritariamente ligada aqui também à experiência ambiental de relação com área verde pública.

Nesse sentido fica confirmada a importância dada à questão ambiental por Bonelli, onde praticamente todos os discursos são ligados à recuperação/relação ambiental. Assim a 
sustentabilidade é utilizada para caracterizar o que seria uma gestão de qualidade, a melhoria da qualidade de vida dos cidadãos seria medida pela promoção de experiências ambientais, e conceitos de sustentabilidade garantiriam desenvolvimento econômico.

De qualquer modo, seja qual for o caminho ou estrutura narrativa seguida, o discurso de Bonelli valoriza a questão do contato com o meio ambiente sustentável. O Parque Madureira é, pois, na sua visão, um projeto de recuperação ambiental para construir o espaço público verde que permitirá à população ter experiências ambientais. A administração da Prefeitura, por sua vez, demonstraria sua aptidão por ser a gestão a aceitar uma ação sustentável de tal magnitude. Como veremos adiante, boa parte desse discurso fundamentará o discurso da Prefeitura, mas para entender seu mosaico é necessário analisar o discurso da RRA.

O escritório de arquitetura responsável pela elaboração do programa do Parque, definido seus objetivos e aparelhos, tem como principal interlocutor seu sócio fundador e principal, o arquiteto Ruy Rezende, que foi a figura pública a aparecer nos vídeos promocionais desenvolvidos pela Prefeitura, assim como fez a divulgação do projeto através de palestras e conferências sobre o tema. Ruy Rezende, bem como seu escritório, publicaram artigos sobre o desenvolvimento do projeto como iniciativa de propaganda. Para efeito dessa pesquisa resolvi analisar o maior e mais completo deles, publicado na forma de um livro ${ }^{4}$, de modo a evitar a análise de documentos repetidos. Apesar da reaparição de discursos encontrados em Bonelli, é importante observar que alguns serão imbuídos de outros sentidos:

1. Gestão: muito similar ou igual à anterior;

2. Sustentabilidade: muito similar ou igual à anterior;

3. Experiências Ambientais: muito similar à anterior, porém Rezende atribui menor valor a elas, podendo ser simplificadas a simples atividades ao ar livre;

4. Recuperação Ambiental: aqui há uma divisão clara entre o discurso da recuperação ambiental e urbana. Para Rezende a recuperação ambiental tem sentido estrito de elementos ambientais como gestão de água, solo, flora e etc. Assim como Bonelli a ocupação irregular é vista como um elemento de degradação ambiental;

5. Recuperação Urbana: na interface entre a recuperação ambiental e o desenvolvimento econômico, é relativo ao aumento do movimento de pessoas no bairro, impulsão do mercado imobiliário e comercial, bem como retirada dos usos urbanos inferiores;

\footnotetext{
${ }^{4}$ REZENDE, R. et al. Parque Madureira Rio+20. [S.1.]: RRA, 2012. Disponível em: <http://rra-websiteassets.s3.amazonaws.com/uploads/production/library_item/pdf/10/MKT-WB-CON-PR-239-LI-R00.pdf>. Acesso em: 23 jul. 2014. 
6. Desenvolvimento Econômico: muito similar ao anterior, ressaltando também a centralidade econômica que o bairro de Madureira possui na cidade;

7. Qualidade de Vida: muito similar ou igual à anterior;

8. Espaço Público: a maior diferença e identidade que do discurso de Rezende, aqui o espaço público não possui exclusividade às experiências ambientais. Ainda que não as exclua, Rezende valoriza o espaço público como lugar do encontro de diferentes pessoas, do mesmo grupo cultural ou não. Muito ligado ao discurso da participação popular, coloca também o espaço público como lugar de exercício da cidadania;

9. Madureira, Identidade: destaque de elementos culturais particulares a Madureira. Rezende utiliza a ideia de Madureira como bairro excepcional, tanto justificando a construção do Parque como utilizando como elemento de valorização do Parque;

10. Participação Popular/Cidadania: Rezende destaca muito a participação popular na construção do projeto do Parque, colocando sempre que os aparelhos foram escolhidos em parceria com a população, essa retórica é utilizada para reforçar a ideia de boa gestão e de espaço público que o Parque conteria. Pós-construção este discurso passa a ser centralizado na questão da alta quantidade de frequentadores do Parque, sendo usado como atestado de aceitação do Parque, o que liga à construção um sentimento de pertencimento.

11. Pertencimento/Valores: similar ao anterior, destaca como a relação da população com o parque tem criado novos valores locais, como a preservação do espaço público;

O primeiro ponto a se observar nos discursos de Rezende é a sua diversidade, sendo destacados vários elementos. Fica claro, no entanto, a forte presença do discurso de que uma boa gestão é aquela que investe na valorização dos espaços públicos, não qualquer área livre, mas a que permite o encontro das pessoas e valorização da cidadania. Isso assinala para uma valorização maior das questões culturais do que ambientais. Ainda que possa parecer intuitivo pensar que a construção de uma área verde funcione necessariamente à valorização da relação homem-meio, isso não é uma causalidade direta ou exclusiva. Como explorado em trabalhos anteriores, o planejamento e construção do Parque do Flamengo, ainda que preocupada com a ambiência, valorizava potencial em estimular as relações sociais homem-homem (CARNEIRO, 2014). O discurso de Rezende, portanto, foge a essa causalidade recolocando as interações sociais como objetivo, com isso cria uma identidade para esse espaço público, retirando-o da condição exclusiva de "área verde livre" colocada por Bonelli.

Ainda que o convívio no espaço público seja a principal condição estabelecida por Rezende para a melhoria da qualidade de vida local, isso não significa que este exclua a 
relação ambiental. Assim coloca que a sustentabilidade e a promoção de experiências ambientais também seriam critérios da melhoria da qualidade de vida. O discurso de Rezende seria então algo como a valorização da relação homem-meio-homem, guardando o valor do Parque em ser esse ambiente.

É interessante constatar que a comparação entre o discurso desses dois atores serve não somente à identificação de novos discursos e estruturas narrativas, mas que suas oposições constituem conflitos de narrativas que criam significados. Ambos tiveram como objeto o mesmo espaço, mas a interpretação e diferentes interesses sobre ele resultam em significantes diversos. A paisagem que Bonelli constrói é de um símbolo da sustentabilidade, que pela sua área verde permite a melhoria da qualidade de vida da população pelo acesso a experiências ambientais. Na perspectiva de Rezende, ainda que o discurso de sustentabilidade seja destacado nos objetivos do escritório de arquitetura, essa paisagem não se define por uma área verde somente. Seu parque é um espaço de convivência e caldeirão cultural que considera típico de Madureira, e que pela adoção de conceitos de sustentabilidade renova as possibilidades e a centralidade simbólica de Madureira. A mistura desses e de outros discursos serão a base para a construção do discurso divulgado pela Prefeitura, como veremos a seguir.

Esse discurso da Prefeitura foi melhor observado no canal oficial do site do projeto "Cidade Olímpica ${ }^{5}$ que oferecia informações de apresentações do Parque em conexão com canal no Youtube $^{6}$ onde hospedava vídeos promocionais. Desses vídeos foram realizados transcrições para melhor acompanhar o discurso enunciado e fazer a análise de conteúdo.

O primeiro ponto a se destacar é a retórica de trazer aspectos culturais e identitários de Madureira para justificar a intervenção pública de criação de um parque sustentável. Não era, portanto qualquer bairro que recebia um parque, mas Madureira. Assim como Rezende colocava no seu discurso, seriam elementos da identidade de Madureira que permitiam potencializar o uso do Parque, enquanto a construção deste promovia uma recuperação ambiental e expansão de áreas livres para experiências ambientais que transformariam a identidade do bairro.

Foi possível observar uma mudança na estrutura discursiva dos vídeos ao longo do tempo e das etapas de conclusão do projeto. Da mesma forma, diferentes atores envolvidos na narração e entrevistas nos vídeos mudam o tom dos discursos. Notadamente percebemos a

\footnotetext{
${ }^{5}$ www.cidadeolímpica.com.br

${ }^{6}$ www.youtube.com/user/riocidadeolimpica
} 
diferença entre os dois atores supracitados. Mauro Bonelli está presente em vários vídeos, e em sua participação reforça o discurso de valorização da sustentabilidade e das experiências ambientais como elemento de transformação de valores do bairro. Enquanto isso, os vídeos com a presença de Rezende se aproximam do discurso da participação popular.

Essa mistura de diferentes atores gera a grande diversidade de discursos encontrados, marcando a transição discursiva da Prefeitura. É possível observar, no início, forte presença do discurso da sustentabilidade é necessário para a construção de valores para a comunidade local. Com a aparição de Rezende esse discurso caminha para a valorização da ideia de que o lazer e o encontro de diferentes no Parque são valores mais importantes. Assim, o discurso final é de que o Parque resulta na melhoria da qualidade de vida dos seus frequentadores pela ampliação das atividades de lazer e cultura, refletindo numa grande sensação de pertencimento local e de satisfação com a administração municipal. Para esse efeito os vídeos finais exploram frequentemente moradores e frequentadores como interlocutores.

Com efeito isso é resultado também por uma transição no discurso de Bonelli. Como colocado, suas falas no início colocam as experiências ambientais como valores centrais a serem protegidos. Contudo seu discurso final não é monopolizado por essas experiências ambientais, destacando também como o Parque funciona como espaço de promoção da sociabilidade entre diferentes pessoas. Essa mudança acompanha também a mudança no discurso oficial municipal. É exemplar, portanto, de como discursos e significados que são selecionados para construir uma narrativa de paisagem podem ser transformados ao longo do processo pela relação com outros atores e seus outros discursos.

\section{CONSIDERAÇÕES FINAIS}

Diante do cenário de obras do "Cidade Olímpica" dificilmente poderia se dizer que o Parque Madureira foi a obra mais impactante. Entretanto, é possível observar como sua construção é importante para a escala do bairro e, para os objetivos dessa pesquisa, como diferentes discursos são criados para competir na criação de narrativas de paisagem.

Os atores aqui analisados construíram discursos diferentes sobre o mesmo Parque, e que vão disputar espaço na esfera da representação para tentar se estabelecer, com maior ou menor sucesso, na visão das pessoas sobre o que seria a paisagem de Madureira. Apesar de algumas semelhanças o olhar diferente de cada um criou suas interpretações originais. Essa situação é inerente ao conceito de paisagem que apresentamos no início. A paisagem pode carregar um 
sentido fortemente visual, mas de nenhuma forma mimética, e é interpretada por cada um de nós a partir de um modo próprio. Isso acontece porque cada um tem seu próprio conjunto de símbolos utilizado para interpretar o espaço ao seu redor.

Assim Bonelli e Rezende constroem narrativas distintas por estarem em posições distintas em relação àquele espaço, são interesses diferentes e conjuntos de significados diferentes que se traduzirão em narrativas diferentes. $\mathrm{O}$ que não exclui a possibilidade de troca de significados e significantes, assim como a mudanças de discursos, tal qual observada na evolução da narrativa de Bonelli. $\mathrm{O}$ espaço de confronto criado pela característica de espaço político da Prefeitura, onde diversos atores são agregados para trabalhar juntos, contribui nessa troca de experiências e significados. Isso pôde ser observado pelo tom dos vídeos oficiais e certamente pode ser encontrado em outros veículos.

Os discursos encontrados aqui certamente continuarão em evolução e poderão ser transformados à medida que se confrontam com outras narrativas e outros significados. Entretanto, por hora e com certas dissonâncias, o discurso que ganhou força é de que tal qual Madureira, o Parque é um espaço público de encontro da diversidade, onde a afinidade local estimula uma boa qualidade de vida. Podemos encontrar algumas divergências de intepretação quanto ao significado de conceitos de sustentabilidade ou experiências ambientais, entretanto fica evidente a estratégia de colocar o Parque como iniciativa de transformação identitária de Madureira.

São esforços, como colocado no início do trabalho, de reafirmação de valores tradicionais ao local, com a inserção de novos elementos e discursos a serem valorizados. No entanto, para definir ao certo a abrangência desses discursos ou sua permanência é necessário expandir e continuar a pesquisa, explorando outros espaços, atores e fontes.

\section{REFERÊNCIAS}

BOURDIEU, P. Sobre o Estado - Cursos no Collège de France (1989-92). Tradução Rosa Freire D’Aguiar. 1. ed. São Paulo: Companhia Das Letras, 2014.

CARNEIRO, Pablo de Oliveira. O Parque do Flamengo no discurso da paisagem carioca. Anais do VII Congresso Brasileiro de Geógrafos, Vitória, 2014. Disponível em: $<$ http://www.cbg2014.agb.org.br/resources/anais/1/1405537118_ARQUIVO_CARNEIRO,P O-OParquedoFlamengonodiscurso.pdf $>$. 
DUNCAN, J. A paisagem como sistema de criação de signos. In: CORRÊA, R. L.; ROSENDAHL, Z. (Org.). Paisagem, Textos e Identidade. Rio de Janeiro: EdUERJ, 2004. p. 91-132.

DUNCAN, J. Após a Guerra Civil: reconstruindo a geografia cultural como heterotopia. In: CORRÊA, R. L.; ROSENDAHL, Z. (Org.). Geografia Cultural - Uma Antologia. 1. ed. Rio de Janeiro: EdUERJ, 2012. v. 1. p. 153-164.

DUNCAN, J.; DUNCAN, N. Landscapes of privilege: aesthetics and affluence in an American suburb. New York: Routledge, 2004.

HALL, P. G. Cidades do Amanhã: uma história intelectual do planejamento e do projeto urbanos no século XX. São Paulo: Perspectiva, 1995. (Estudos 123).

MORAES, R. Análise de Conteúdo. Revista Educação, v. 22, n. 37, p. 7-32, 1999.

REZENDE, R. et al. Parque Madureira Rio+20. [S.1.]: RRA, 2012. Disponível em: $<$ http://rra-website-assets.s3.amazonaws.com/uploads/production/library_item/pdf/10/MKTWB-CON-PR-239-LI-R00.pdf>. Acesso em: 23 jul. 2014.

RIBEIRO, R. W. Paisagem, Patrimônio e Democracia: novos desafios para as políticas públicas. In: RODRIGUES, J. N.; CASTRO, I. E. DE; RIBEIRO, R. W. Espaços da Democracia: para a agenda de Geografia Política Contemporânea. Rio de Janeiro: Bertrand Brasil, 2013.

RIBEIRO, R. W. Possibilidades e limites da categoria de paisagem cultural para a formação de políticas de patrimônio. In: CUREAU, S.; AKEMI, S.; SOARES, I. V. P. (Org.). Olhar multidisciplinar sobre a efetividade da proteção do patrimônio cultural. Belo Horizonte: Fórum, 2011. p. 254-267.

ROSSI, U.; VANOLO, A. Urban political geographies: a global perspective. 1st. ed. Thousand Oaks, CA: SAGE Publications, 2011.

SANTOS, M. A Natureza do Espaço: técnica e tempo - razão e emoção. 1. ed. São Paulo: Hucitec, 1996.

SAUER, C. O. A morfologia da paisagem. In: CORRÊA, R. L.; ROSENDAHL, Z. (Org.). Paisagem, Tempo e Cultura. Rio de Janeiro: EdUERJ, 1998. p. 12-74.

VERDUM, R. et al. (Org.). Paisagem: leituras, significados transformações. 1a edição ed. Porto Alegre: Editora da UFRGS, 2012. (Série Estudos rurais).

VIEIRA, M. E. M. O Jardim e a paisagem: espaço, arte, lugar. São Paulo: Annablume, 2007. 